\title{
SINTAXE GERATIVA E ENSINO DE GRAMÁTICA: CONTRIBUIÇÕES DE ESTUDOS EM PB DIALETAL
}

\author{
GENERATIVE SYNTAX AND GRAMMAR TEACHING: \\ CONTRIBUTIONS OF STUDIES ON DIALECTAL BP
}

Bruna Karla PEREIRA ${ }^{1}$

Resumo: Neste trabalho, investiga-se como pesquisas sobre português brasileiro (PB) dialetal, em sintaxe gerativa, podem contribuir para o ensino de gramática. Para isso, faz-se inicialmente uma revisão dos estudos sintáticos de PB dialetal e posteriormente uma revisão dos estudos que tratam das contribuições da teoria gerativa para o ensino de gramática. Mostra-se que, após conhecerem pesquisas em sintaxe sobre PB dialetal, os professores obterão: uma comparação científica e analítica entre pelo menos dois sistemas, padrão e não padrão; entendimento de que as estruturas são regidas por universais; um modelo de análise no qual poderão se basear em suas reflexões sobre os fatos linguísticos; reconhecimento da competência gramatical que $o$ aluno traz consigo para a escola; possibilidade de elaboração de formas de intervenção para ensino da gramática padrão, sem desvalorizar ou estigmatizar variedades não padrão; habilidades metalinguísticas e epilinguísticas para poderem intermediar a aquisição dessas habilidades entre os alunos, dentre outros. Conclui-se, portanto, que estudos em sintaxe gerativa têm a contribuir para a formação de professores e em consequência para o ensino de gramática na educação básica.

Palavras-chave: Sintaxe gerativa. Ensino de gramática. PB dialetal.

\begin{abstract}
This paper investigates how studies of dialectal Brazilian Portuguese (BP), in generative syntax, may contribute to grammar teaching. In order to do this, I firstly review syntactic studies on dialectal BP and then studies on the contributions of the generative theory to grammar teaching. I show that, after getting to know these researches on dialectal BP, teachers will obtain: a scientific and analytical comparison between the two systems, standard and non-standard BP; understanding of the fact that the structures are governed by universals; a theoretical and methodological model for developing an accurate reflection on linguistic data; acknowledgment of the internal grammatical competence that the students are endowed with before getting to the school; ways of intervention in teaching the standard grammar without stigmatizing non-standard varieties; skills on linguistic analysis in order to supervise the further acquisition of these skills among their students; etc. In sum, studies on generative syntax contribute to teachers' education and grammar teaching at school.
\end{abstract}

Keywords: Generative syntax. Grammar teaching. Dialectal BP. 
- | Sintaxe gerativa e ensino de gramática: contribuições de estudos em PB dialetal

\section{Introdução}

Este trabalho objetiva investigar como os estudos sintáticos de português brasileiro (PB) dialetal ${ }^{2}$ podem contribuir para o ensino de gramática, na formação de professores e na educação básica.

Com base em Pilati et al. (2011), Lemle e Figueiredo Silva (2013), Foltran (2013), Kato (2013), Lobato (2015), Silva e Pilati (2016), dentre outros, que se pautam no conceito de gramática como competência linguística internalizada, entende-se que o aluno, ao chegar à escola, já domina as regras de uma língua e que esse conhecimento poderá ser utilizado para potencializar o aprendizado da variedade culta ${ }^{3}$.

Sendo assim, neste trabalho, investiga-se de que modo a descrição formal de variedades do PB, especialmente do dialeto mineiro (VITRAL; RAMOS, 2006, RAMOS; COELHO, 2013; PEREIRA, 2016a, 2016b, 2017, 2018a, 2018b), pode contribuir para a execução dessa proposta. Trata-se, portanto, de um trabalho que contém três etapas. A primeira cataloga e revisa estudos da sintaxe do PB dialetal, desenvolvidos na abordagem gerativa. Por sua vez, a segunda cataloga e revisa estudos que tratam das contribuições da teoria gerativa para o ensino de gramática. A terceira e principal faz uma intersecção entre as duas primeiras etapas e investiga de que modo estudos do PB dialetal podem contribuir para o ensino de gramática.

\footnotetext{
2 Por PB dialetal, entende-se variedade não padrão, característica de alguma região do Brasil. Por uma questão de recorte, boa parte das formas não padrão, analisadas na primeira seção deste trabalho (tais como "ques menino esperto", "a vida suas", "cadas coisa estranha", "umas meia hora" e "quantos que custa"), foi extraída de dados do dialeto mineiro.

3 Neste trabalho, usamos indistintamente "norma padrão", "norma culta", "variedade padrão" e "variedade culta" para representar a variedade de prestígio a ser aprendida na escola, para uso em situações monitoradas de fala e escrita. No entanto, vale destacar que a literatura apresenta distinções. Por exemplo, para Faraco (2008), norma padrão, norma culta e norma curta são conceitos distintos associados à representação que se tem de norma. Para o autor, norma padrão é uma abstração, prescrita na GT. Norma culta, por sua vez, representa a norma usada por falantes escolarizados, mas difere da norma padrão por ser relativamente variável e admitir formas que esta não admite, como a regência "namorar com". Por último, norma curta é apresentada na mídia, com noções de certo e errado, que desqualificam e tratam com preconceito qualquer forma que se desvencilhe de preceitos dogmáticos prescritos por um ideal de falar "bem". De acordo com Coelho et al. (2015, p. 141), deve-se "ensinar a norma culta (e não a norma padrão e muito menos a norma curta), não no sentido de exigir que o aluno substitua uma norma (a dele, vernacular) por outra, mas no sentido de capacitá-lo a dominar outras variedades para que possa adequar seu uso linguístico a diferentes situações". Apesar dessa diferença, é praticado, na literatura, o uso indistinto de "norma culta" e "norma padrão", como no trecho a seguir: "Não se trata, então, de ensinar a língua materna ao aluno e, sim, de ensinar a ele uma determinada variedade da língua (a variedade padrão ou norma culta)" (GÖRSKI; COELHO, 2009, p. 83, grifo nosso).
} 
Especialmente, objetiva-se mostrar: (i) como essa metodologia de análise, com rigor científico, pode contribuir para a aquisição de habilidades metalinguísticas e epilinguísticas (de reflexão, sistematização, categorização, descrição e análise) por parte dos professores em formação, que deverão posteriormente intermediar a aquisição de tais habilidades entre seus alunos, conforme previsto nos PCNs; (ii) como o conhecimento da gramática da variedade falada pelo aluno pode contribuir para o aprendizado da gramática da variedade culta; (iii) como o conhecimento da descrição da gramática da variedade falada pelo aluno pode contribuir para a compreensão do funcionamento da gramática da variedade culta; (iv) como dialetos do PB têm valor e importância em trabalhos científicos na área da Linguística.

Assim, este artigo se organiza em três partes: a primeira aborda trabalhos que tratam do PB dialetal; a segunda discute trabalhos em perspectiva gerativa sobre ensino de gramática; e a terceira analisa como estudos de PB dialetal, em sintaxe gerativa, podem contribuir para o ensino de gramática.

\section{Estudos sintáticos de PB dialetal}

Esta seção abordará estudos sobre PB dialetal. Para fins de recorte ${ }^{4}$, selecionou-se um tema específico, qual seja, a concordância nominal. A concordância nominal é um dos tópicos fundamentais no ensino. Nesta subseção, abordaremos estruturas recorrentes de concordância em variedades de PB não padrão e faremos um apanhado da análise proposta para explicar as regras que subjazem a marcação de plural nessas variedades. Dessa forma, será descrito o funcionamento dessas regras em PB não padrão, de modo geral, e em estruturas do dialeto mineiro, de modo mais específico.

Com base em Danon (2011) e Norris (2014), Pereira (2017) demonstrou que NumP funciona, no PB não padrão, como uma fronteira sintática na qual sintagmas à esquerda de cardinais são marcados com o morfema de plural, enquanto sintagmas à direita são não marcados. Essa regra pode ser observada em (1), exemplos de concordância em PB não padrão, e em (2), estruturas recorrentes no dialeto mineiro (NUNES, 2007, PEREIRA, 2016a).

\footnotetext{
4 Reitero que se trata de um recorte, pois há, na literatura, estudos formais de dialetos do PB com enfoque em outros fenômenos morfossintáticos. Por exemplo, do volume organizado por Ramos e Coelho (2013), destacase o capítulo de Duarte e Diniz (2013) sobre redobro pronominal, em estruturas como "Eu te amo você". Além disso, Vitral e Ramos (2006) observam o processo de gramaticalização, a partir de uma perspectiva formal, dos itens "senhor", "você" e "eles", que são reduzidos a "sô", "cê" e "es", respectivamente. Ainda outro trabalho é o de Scher, Barbosa e Armelin (2014) sobre construções dativas como "A Maria deu o Pedro um livro".
} 
- | Sintaxe gerativa e ensino de gramática: contribuições de estudos em PB dialetal

(1) a. os (dois) outro carro branco (PEREIRA, 2017, p. 86)

b. os outros (dois) carro branco (PEREIRA, 2017, p. 86)

(2) a. Ques (duas) paisagem bonita! (PEREIRA, 2016a, p. 582)

b. Ques (duas) ferramenta você usou? (PEREIRA, 2016a, p. 582)

Pereira (2018b, p. 134) observa ainda que "variedades do PB, especialmente a falada em Minas Gerais, evidenciam um padrão diferente de concordância em número em DPs com o possessivo de $2^{a}$ pessoa. Nesse padrão, não há concordância em número entre possessivo e nome". Por exemplo, em (3), o possessivo "suas" está no plural e não concorda com os itens "a" e "gerência", que não recebem marca de número.

(3) A gerência suas só atende clientes grandes (PEREIRA, 2018b, p. 134).

A autora explica que "o PB dialetal reanalisa traços de número nos possessivos de $2^{\text {a }}$ pessoa como sendo o número da pessoa e como sendo interpretável e valorado. Portanto, o morfema de plural '-s', em possessivos pós-nominais de $2^{\text {a }}$ pessoa, não reflete concordância nominal em número" (PEREIRA, 2018b, p. 144).

Para discutir a razão da predominância dessa reanálise em posição pós-nominal, a autora defende que a regra de cardinais como fronteira sintática se aplica: em sentenças como (4a), "o artigo 'os' e o possessivo 'seus', que precedem o cardinal, são marcados com o morfema de plural, enquanto o nome 'carro' e o adjetivo 'novo', que seguem o cardinal, são não marcados" (PEREIRA, 2018b, p. 144).

(4) a. Não vi [os seus (dois) carro novo] (PEREIRA, 2018b, p. 144).

b. *Não vi [os seu carro novo] (PEREIRA, 2018b, p. 144).

“Em posição pré-nominal, o possessivo precede cardinais [(4a)]. Por essa razão, é sempre marcado com o morfema de plural, em DPs plurais" (PEREIRA, 2018b, p. 144). Em contrapartida, possessivos em posição pós-nominal estão livres dessa marca para concordância nominal, pois estão à direita de NumP, o que propicia a reanálise:

[...] possessivos prenominais estão em sintagma (DP) localizado acima de NumP; como tal, devem receber a marca de plural associada à concordância nominal. Por outro lado, possesivos pós-nominais estão em um sintagma (PossP) localizado abaixo de NumP; como tal, não devem receber essa marca. Livre de tal marca, o possessivo em posição pós-nominal é mais suscetível à reanálise mencionada. (PEREIRA, 2018b, p. 147). 
Para explicitar essas duas posições, observa-se a seguir a representação arbórea com possessivo preposto ${ }^{5}$ e outra com possessivo posposto:

(5)

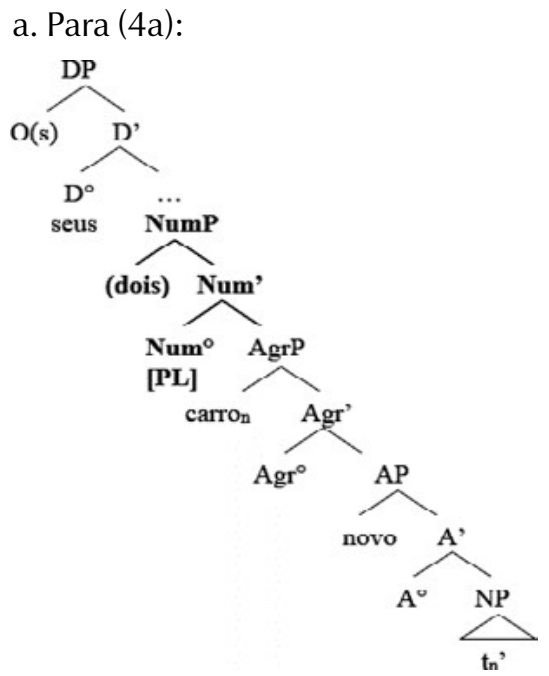

(5) b. Para (3):

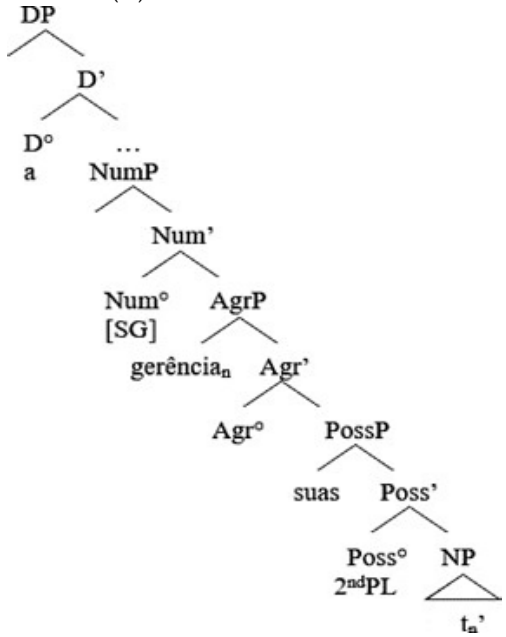

Fonte: Pereira (2016b, p. 225)

Além disso, com base em Kayne (2005), Pereira (2017) observou que estruturas que apresentam restrições à presença de cardinais dispõem de outra categoria, um silent noun, com traços de plural. Esse silent noun funciona como fronteira sintática na distribuição do morfema de plural no PB, como se observa em (6), estrutura recorrente no dialeto mineiro, e em (7), estrutura encontrada em PB não padrão de modo mais geral.

(6) Quantos [AMOUNT of] (real) que custa? (PEREIRA, 2017, p. 102).

(7) Levou umas [HOUR of] meia hora pra dor passar (PEREIRA, 2017, p. 99).

Além disso, esse silent noun no plural pode ser seguido por uma preposição, o que permite que sintagmas encaixados na posição de complemento da preposição estejam no singular, como "meia hora", enquanto sintagmas à esquerda do silent noun estejam no plural, como "umas".

À semelhança de (6) e (7), (8) fornece evidências para a hipótese segundo a qual existe uma categoria, entre $\mathrm{D}$ e $\mathrm{N}$, que dispõe de traços de número valorados no PB.

5 Em (5a), o possessivo é núcleo de D, enquanto o artigo é Spec,DP, porque, segundo Pereira (2018b, p. 145), quando o artigo definido coocorre com possessivos prenominais, "o artigo definido [...] não é marcador de definitude, mas apenas um expletivo" (COSTA; FIGUEIREDO SILVA, 2006, p. 40, tradução minha). Nessa visão, sendo um determinante expletivo, o artigo definido pode ser omitido ou aparecer sem marca de plural. Uma análise possível desses fatos é que o artigo definido, quando coocorre com possessivos prenominais, forma, com o possessivo prenominal, um único sintagma (DP) no qual o artigo é o especificador (Spec,DP), enquanto o possessivo é o núcleo (D). A evidência mais robusta disso é a adjacência entre o artigo e o possessivo prenominal [...]. 
- | Sintaxe gerativa e ensino de gramática: contribuições de estudos em PB dialetal

(8) a. "Já peguei cadas engarrafamento ali (na BR-381)!" (PEREIRA, 2018a, p. 88).

b. "integrantes do MP têm de fazer reciclagem a cadas três anos" (PEREIRA, 2018a, p. 87).

Pereira (2018a) investiga estruturas nominais do português do Brasil (PB) não padrão em que "cada" é flexionado com o morfema "-s" de plural, enquanto sintagmas que o seguem podem não receber qualquer marca de plural. Para analisar esses fatos, a autora argumenta que DPs com "cadas" projetam um silent noun SET, como se observa em (9), que veicula leitura de conjunto bem como traços de plural valorados. Nesse caso, "cadas" pode ser interpretado como such (8a) ou every (8b), em vez de each, e pode ser seguido por nome ou por cardinal $\geq 2$ (mais nome). Portanto, porque "cadas" precede SET, recebe marca de plural "-s". Esse silent noun plural é seguido de uma preposição, o que permite a seu NP complemento ser singular.

(9) a. Para (8a): "cadas engarrafamento"

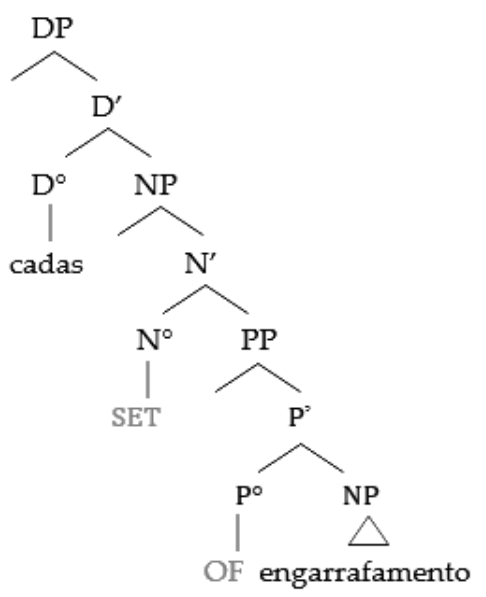

Fonte: Adaptado de Pereira (2018a, p. 100) b. Para (8b): "cadas três ano(s)"

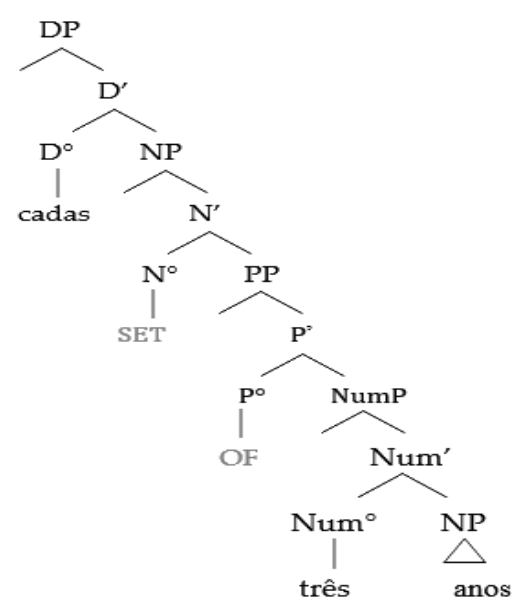

Fonte: Adaptado de Pereira (2018a, p. 99)

Desse modo, Pereira (2016a, 2016b, 2017, 2018a, 2018b) considera que cardinais e silent nouns funcionam como uma fronteira dividindo o DP, em PB não padrão, em dois domínios, de forma que sintagmas à sua esquerda são marcados com o morfema de plural, enquanto sintagmas à sua direita são não marcados. Essa regra explica por que alguns elementos do DP recebem marca de plural e outros não. Trata-se de uma regra sintática, pois depende da posição do constituinte na estrutura do DP. Trata-se ainda de um parâmetro encontrado em outras línguas, tais como, o finlandês e o estoniano, conforme estudos de Danon (2011) e Norris (2014).

Logo, existe uma regra subjacente à concordância nominal em PB não padrão que a difere do português padrão. Conhecer as diferenças entre essas regras é passo 
importante quando se trabalha com o tema da concordância, em sala de aula. Dessa forma, as descrições de PB dialetal apresentam avanço nesse aspecto, pois trazem reflexões e análise das estruturas presentes na fala dos alunos, para efetivação e compreensão desse paralelo entre as variedades em questão.

Sem objetivar esgotar os estudos de fenômenos sintáticos em PB dialetal, esta seção apresentou exemplos de ocorrências de concordância nominal contempladas em estudos linguísticos contemporâneos e que fazem parte da fala dos alunos que chegam às escolas. Tais estudos explicitam o conhecimento linguístico internalizado e os arranjos sintáticos disponíveis, além de descreverem estruturas não contempladas nas gramáticas tradicionais, mas recorrentes na fala. Na terceira seção deste artigo, será discutido como tais estudos podem contribuir para o ensino de gramática. Antes, porém, será evidenciado como estudos em sintaxe gerativa podem desempenhar esse papel.

\section{Estudos gerativistas e ensino de gramática}

Os estudos dentro da abordagem gerativa baseiam-se no conceito de Gramática Universal (GU) ou Faculdade da Linguagem', no sentido de Chomsky (1986) e Hauser, Chomsky e Fitch (2002), da qual o ser humano é dotado. Além desse conceito, há também a língua I, isto é, a língua que o falante adquire após receber input na comunidade. A partir desse input, o falante aciona os parâmetros disponíveis nos princípios universais presentes como componente biológico e mental na Gramática Universal (GU). Por sua vez, "A competência linguística é a capacidade humana que torna fundamentalmente possível que todo ser humano seja capaz de interiorizar um ou vários sistemas linguísticos, isto é, uma ou várias gramáticas" (MIOTO; SILVA; LOPES, 2007, p. 22). Nesse sentido, Gramática Universal é o conhecimento internalizado que predispõe o ser humano a adquirir língua.

Assim, ao chegar à escola, o aluno já tem conhecimento da gramática de uma língua. Além dessa gramática, durante seu período escolar, espera-se que o aluno aprenda a gramática da variedade de prestígio, dominada pelos falantes escolarizados e conhecida como norma culta. Neste trabalho, abordaremos questões que concernem à utilização do conhecimento que o aluno tem da variedade que ele fala para exteriorização do conhecimento linguístico implícito e até mesmo para intervenções no aprendizado da

6 "O processo de aquisição de linguagem, então, é tido como a 'formatação' da Faculdade da Linguagem através da fixação dos valores dos parâmetros previstos na UG [...] a UG é, nesse sentido, um quadro do estágio inicial da aquisição (conhecido como $S_{0}$ ) e o seu produto seria o estágio final da aquisição, isto é, o estágio em que a criança atinge a gramática adulta de sua língua $\left(\mathrm{S}_{\mathrm{s}}\right)$ (do inglês stable stage)" (MIOTO; SILVA; LOPES, 2007, p. 33):

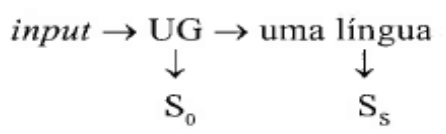


- | Sintaxe gerativa e ensino de gramática: contribuições de estudos em PB dialetal

variedade culta. Portanto, a esse respeito, valoriza-se o conhecimento de sua variedade, apontando-se o que há de semelhante e o que há de diferente entre elas.

De acordo com Lemle e Figueiredo Silva (2013, p. 114):

Assim pensando, o ensino da Variedade Oficial precisa seguir os métodos de ensino utilizados nos cursos de línguas estrangeiras. Nesses cursos, os professores não menosprezam a língua nativa dos alunos, mas a respeitam e aproveitam. No ensino, eles tentam realçar os pontos em que as gramáticas da primeira língua e da língua estrangeira coincidem e os pontos em que diferem.

Lobato (2015, p. 51) também afirma que:

O que se deveria fazer é alfabetizar em português o aluno, mas através do uso da língua que ele conhece e aprendeu em casa. Desse modo, não estará desestimulando a aprendizagem nem se estará formando pessoas com vistas ao fracasso.

Em vista disso, dentro de uma perspectiva gerativista, entende-se que a variedade ${ }^{7}$ falada pelo aluno e a variedade que ele precisa aprender possuem cada qual suas regras e complexidades, independentemente do julgamento de valor social imposto a cada uma delas. Desse modo, os professores em formação precisam se convencer de que as variedades não padrão possuem regras e são passíveis de descrição e sistematização assim como a variedade padrão: "E é aqui que está uma grande dificuldade: entender que todas as variedades são línguas, com a mesma complexidade, todas dotadas de sistemas de leis (no sentido que as ciências naturais dão ao termo 'leis'), todas passíveis de estudo e de sistematização" (LEMLE; FIGUEIREDO SILVA, 2013, p. 113). Além disso, precisam tomar conhecimento dos diversos trabalhos que a literatura apresenta de descrição e análise de variedades não padrão.

Para Kato (2013), existem dois grandes entraves no ensino da norma culta. O primeiro é a distância que há entre língua falada e língua escrita: "no Português do Brasil (PB) existe um fosso de tal ordem que, para a criança aprender a ler e a escrever, ela enfrenta a tarefa da aprendizagem de uma língua estrangeira" (KATO, 2013, p. 149). O segundo grande entrave é a "ausência de contacto com a escrita de livros de histórias pelas crianças, nas classes sociais em que os pais são iletrados" (KATO, 2013, p. 149). Por isso, a autora sugere

\footnotetext{
7 De acordo com Lemle e Figueiredo Silva (2013, p. 114), “todas as variedades são línguas, dotadas de gramática [...] e a variedade oficial é uma língua estrangeira para a grande maioria de - ou todos - os brasileiros".
} 
que o primeiro passo para encurtar a distância referida é que, nas escolas, os professores leiam para as crianças, de modo que elas possam ter oportunidades de estarem expostas à língua escrita. É ainda devido a essa distância que a autora concorda que o aprendizado da norma culta se assemelha ao aprendizado de uma L2.

De acordo com Kato (2013, p. 150), a língua I (interna) do falante letrado possui uma gramática nuclear (GRN), "resultado da aquisição espontânea da criança [...] comum a todos os brasileiros", além de uma segunda gramática, isto é, "um sistema periférico de regras que se aproxima daquele de uma gramática dos brasileiros no século passado" (KATO, 2013, p. 150) e que se assemelha a uma segunda língua (L2).

Sendo assim, para a autora:

Para formar docentes capacitados a atuar na escola brasileira, venho sugerir, neste trabalho, que se pode subsidiar a escola em três tipos de pesquisa: a) uma descrição do conhecimento linguístico que a criança traz para a escola; b) uma descrição da língua-I dos escritores contemporâneos; e c) uma descrição da forma como os aprendizes escolares bem-sucedidos chegam perto desse conhecimento. (KATO, 2013, p. 161).

Por sua vez, Foltran (2013) reconhece ser indubitável a necessidade de ensino de gramática tanto nos cursos de Letras quanto na educação básica. Para a autora, o ensino deve levar o aluno a ter autonomia, para, por exemplo, ser capaz de consultar um dicionário. Para executar essa tarefa, a autora mostra que tanto o conhecimento da nomenclatura quanto o conhecimento de princípios de análise gramatical são indispensáveis. Com efeito, a consulta a uma palavra como "procrastinou" depende do conhecimento de que se trata de um verbo, e, portanto, depende do conhecimento de classes de palavras. A consulta ao dicionário depende ainda do conhecimento de que, para buscar tal palavra, é necessário que ela seja passada para o infinitivo "procrastinar". Além disso, ao adentrar na leitura do verbete, haverá expressões como "v.t.d." que envolvem conhecimentos sobre regência, dentre outros. Logo, é indiscutível para a autora a necessidade do ensino de gramática.

No entanto, não se deve restringir à nomenclatura quando se define que o ensino de gramática deve ser veículo para se explicitar o conhecimento que o falante tem da língua que ele fala. Portanto, no ensino de gramática, o aluno deve aprender a explicitar as condições e os arranjos linguísticos possíveis para expressão do significado.

Mais do que definições e rotulações, o trabalho com a língua pode ser feito da mesma forma que em Biologia se observa o interior de um sapo para estudar 
- | Sintaxe gerativa e ensino de gramática: contribuições de estudos em PB dialetal

as partes, o funcionamento dos órgãos. Dissecar a sentença, o sintagma, é explicitar a sua constituição, é entender melhor o seu funcionamento (FOLTRAN, 2013, p. 177).

Nessa perspectiva, o aluno do curso de Letras precisa conhecer muito mais do que aquilo que ele deve efetivamente ensinar:

[...] ensinar apenas o que se acha que o professor vai ensinar é trabalhar com uma visão muito estreita de professor e de ensino. Sem sombra de dúvidas, o conhecimento do professor deve ir muito além, mas muito além mesmo, daquilo que ele ensina. Isso faz uma diferença brutal na atuação desse profissional em sala de aula. (FOLTRAN, 2013, p. 173).

Sobretudo, a autora alerta para o fato de que, se for opção o ensino de gramática tradicional, não deve ser ingênuo o trato dessa abordagem, em virtude das lacunas descritivas e metodológicas que ela apresenta. Ainda, para a autora,

Ensinar gramática é operar com os conhecimentos que o falante tem de sua própria língua e torná-los explícitos. É levar à percepção de que, apesar de termos um número infinito de possibilidades de sentenças na língua, temos um número bastante reduzido de estruturas linguísticas. Levar ao conhecimento e descrição dessas estruturas é um trabalho instigante, além de ser um momento privilegiado para o desenvolvimento do pensamento científico. (FOLTRAN, 2013, p. 175).

Segundo Foltran (2013, p. 173): "a escola precisa aprender com a ciência, com qualquer ciência, a trabalhar com a dúvida, a questionar, a arriscar hipóteses. Seria esse o ganho que teríamos num exercício como esse. E esse é o único modo de avançar-se em ciência".

Foltran (2013) aborda vários exemplos em que isso pode ser aplicado. Um deles trata de uma estrutura com ambiguidade sintática como (10) abaixo.

(10) A professora de literatura americana (FOLTRAN, 2013, p. 175).

Foltran (2013) explica que os falantes são capazes de reconhecer a ambiguidade presente em (10), que consiste em "americana" se referir aos termos "professora" ou "literatura". A abordagem gerativa, por sua vez, pode demonstrar como essa ambiguidade é derivada, a partir de razões estruturais. 
Desse modo, na leitura em que a literatura é americana, tem-se um arranjo sintático no qual "americana" faz parte do mesmo constituinte de "literatura", como se observa no diagrama (11a). Por sua vez, na leitura em que a professora é americana, tem-se um outro arranjo sintático no qual "americana" é gerada em posição mais alta na estrutura, dentro do mesmo constituinte de "professora", como se observa no diagrama (11b).

(11)

a.

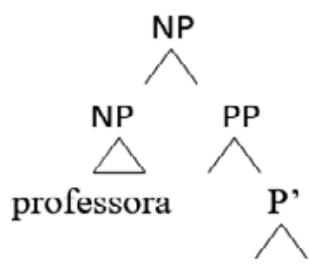

de NP

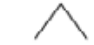

NP AP

literatura americana
(11)

b.

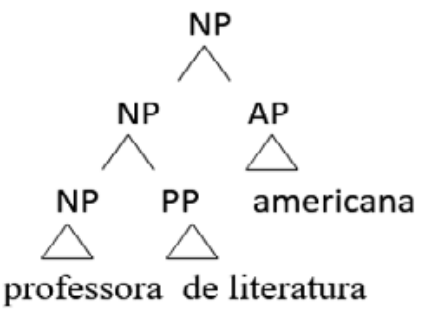

Fonte: Adaptado de Foltran (2013, p. 177)

Sendo assim, é tarefa do ensino de gramática observar, reconhecer e montar as peças desse "quebra-cabeça" das estruturas linguísticas. "Ao ensino, então, não caberia 'ensinar' a língua, mas trazer à consciência o conhecimento já possuído, tornando o aluno apto a manipular de maneira reflexiva a estrutura de seu idioma" (SILVA; PILATI, 2016, p. 233). Também para Quarezemin (2017, p. 75):

As aulas de gramática desde muito cedo devem (i) propiciar ao aluno uma perspectiva reflexiva e consciente da língua, (ii) suscitar o espírito de investigação, de curiosidade e de questionamento frente à linguagem que ele emprega no seu dia a dia, (iii) desenvolver a aprendizagem das principais estruturas e dos mecanismos fundamentais da língua, e devem, ainda, (iv) permitir a abordagem do tipo experimental. Por que não um laboratório de gramática na escola? Um espaço em que o professor e o aluno possam observar, testar, analisar os dados da língua, incluindo todas as variedades do português brasileiro. Um espaço que possibilite maior reflexão sobre o conhecimento explícito trabalhado nas aulas de língua portuguesa.

Nesse sentido, Foltran, Knöpfle e Carreira (2017, p. 30) mostram que o estudo da gramática deve ser entendido "como método científico que nos faculta a compreensão de como uma língua funciona". Com efeito, para Ferreira e Vicente (2015, p. 435): 
- | Sintaxe gerativa e ensino de gramática: contribuições de estudos em PB dialetal

Um dos maiores obstáculos concernentes ao estudo de fenômenos da língua reside na frequente abordagem não-científica dos fenômenos por parte da tradição gramatical [...] Apresentar definições desse tipo aos estudantes figura entre os entraves para uma verdadeira reflexão sobre a língua, uma vez que não suscita o entendimento de que há um mecanismo operante em questão, a respeito do qual o aluno pode fazer inferências, aferir hipóteses ou gerar resultados.

Além desse problema, conforme afirma Tescari Neto (2017, p. 131), os PCNs

[...] optaram por deslocar o foco do ensino de gramática a partir do texto para um foco no funcionamento discursivo do texto, com um esvanecimento do papel do ensino de gramática nas aulas de português [...] o foco das aulas de língua portuguesa passa a ser o processo de construção textual [...] À gramática restaria um papel de ancilar, condenada que estaria, agora, a um enquadramento de mera serviçal à prática de análise do texto.

Face a esse destaque que tem sido dado ao texto no ensino, em uma visão sociointeracionista, em detrimento de uma abordagem inatista, Pilati (2018, p. 12) defende que:

O caráter multifacetado das línguas é base epistemológica da linguística moderna e foi reconhecido desde que a linguística foi instituída como ciência. Apresentar uma visão unidimensional de um fenômeno multidimensional negligencia, portanto, a episteme do próprio campo do saber [...] Ao desconsideramos o componente biológico das línguas humanas, privamos nossos alunos de conhecimentos relevantes acerca de sua natureza humana e de descobertas da ciência contemporânea.

Assim, na abordagem gerativa, "ensinar" gramática é trazer à consciência conhecimentos internalizados sobre as regras de funcionamento das estruturas linguísticas (VICENTE; PILATI, 2012; FOLTRAN, 2013). Nessa perspectiva, a função da escola é a de ensinar a norma de prestígio, sem desvalorizar as variedades linguísticas trazidas pelos alunos e o conhecimento internalizado das regras dessas variedades. Nesse sentido, o ensino da norma de prestígio deve se dar como ensino de L2, em virtude da distância entre a norma culta e as variedades não padrão, como apontado por Kato (2013).

Além disso, a consideração do conhecimento prévio do aluno a que se referem os PCNs é explicitada, na abordagem gerativa, como a consideração da competência 
linguística (VICENTE; PILATI, 2012) inata (estágio inicial da aquisição) e do conhecimento da língua I adquirida após exposição ao input da variedade dominada pelo aluno.

Assim, pretende-se contornar um dos vários problemas que o ensino de gramática enfrenta que está no domínio conceitual, pois são utilizados os conceitos da gramática tradicional. Estes apresentam circularidade, limitações, incoerências, vagueza e falta de critérios linguísticos, por exemplo, na definição de substantivo como a palavra que designa o ser ou de sujeito como o ser a respeito do qual se fala.

Com a teoria gerativa, pode-se contribuir para o ensino de gramática a partir da elaboração de conceitos com critérios linguísticos, com análise rigorosa e ao mesmo tempo minimalista das estruturas. Por exemplo, em vez de "termos da oração", adotase o conceito de sintagma que permite a identificação do núcleo e da recursão de sintagmas dentro de sintagmas, formando "uma unidade estrutural" (KENEDY, 2013, p. 75). Outro exemplo seria que, em vez da listagem de uma série de classificações de tipos de sujeito como oculto, inexistente e indeterminado, permite-se a simplificação dessas três categorias em apenas uma, sujeito nulo (KENEDY, 2013). Dessa forma, o conhecimento linguístico internalizado dos alunos não deve ser negligenciado (PILATI et al., 2011) e deve ser permitida a realização de atividades que possibilitem a observação, a reflexão, o levantamento de hipóteses e a sistematização dos fatos linguísticos.

Em suma, em uma revisão das injunções dos pesquisadores gerativistas no ensino de gramática, destacam-se os seguintes pontos:

1) Ao chegar à escola, o aluno tem conhecimento de uma língua;

2) A variedade culta deve ser ensinada como $2^{\mathrm{a}}$ língua, sendo apresentados os aspectos das estruturas linguísticas comuns e diferentes entre as variedades em questão;

3) O conhecimento da gramática da variedade falada pelo aluno pode ser utilizado para potencializar o aprendizado da variedade culta;

4) Os professores em formação, alunos de Letras, precisam estudar mais do que aquilo que vão efetivamente ensinar aos seus alunos na educação básica;

5) Ensinar gramática é ensinar como exteriorizar e trazer para a consciência conhecimentos do funcionamento linguístico que os falantes já dominam em sua língua I. 
- | Sintaxe gerativa e ensino de gramática: contribuições de estudos em PB dialetal

6) É inquestionável a necessidade do ensino de gramática na escola como forma de instrumentalizar o aluno para a autonomia intelectual e para o exercício da cidadania;

7) O ensino da norma padrão não deve ser confundido com ensino de gramática, que parte da observação, reflexão, categorização e análise das estruturas linguísticas, mesmo que não seja a partir de formas da norma padrão;

8) O aparato teórico e epistemológico da teoria gerativa contribui para a elaboração de conceitos com critérios linguísticos, com análise rigorosa e ao mesmo tempo minimalista das estruturas;

9) É necessário promover o saber científico na sala de aula, ao considerar o componente biológico e humano da aquisição linguística;

10) Busca-se executar "projetos, em que competências intelectuais como a análise, a classificação, a analogia, a inferência, sejam desenvolvidas por procedimentos de formulação de hipóteses e raciocínio inferencial sobre dados linguísticos" (PILATI et al., 2011, p. 400).

\section{Contribuições dos estudos sintáticos de PB dialetal para o ensino de gramática}

Esta seção estabelece uma interlocução entre: as injunções da teoria gerativa para o ensino de gramática, os estudos de PB dialetal e os PCNs, de modo a mostrar as contribuições dos estudos de PB dialetal para o ensino de gramática.

De acordo com os PCNs de língua portuguesa:

Tomar a língua escrita e o que se tem chamado de língua padrão como objetos privilegiados de ensino-aprendizagem na escola se justifica, na medida em que não faz sentido propor aos alunos que aprendam o que já sabem. Afinal, a aula deve ser o espaço privilegiado de desenvolvimento de capacidade intelectual e linguística dos alunos, oferecendo-lhes condições de desenvolvimento de sua competência discursiva. Isso significa aprender a manipular textos escritos variados e adequar o registro oral às situações interlocutivas, o que, em certas circunstâncias, implica usar padrões mais próximos da escrita. (BRASIL, 1998, p. 30, grifos nossos).

Dessa forma, não se pode perder de vista que o principal objetivo da escola é possibilitar que os alunos tenham proficiência na variedade de prestígio, a norma culta, 
para que sejam capazes de transitar pelas diferentes situações comunicativas, em especial, as situações mais formais que exigem competência na língua padrão. Esse bilinguismo também está previsto por Lemle e Figueiredo Silva (2013, p. 113, grifo nosso), quando afirmam que:

À etapa de normativização [...] deve-se seguir a construção de um sistema escolar no qual essa variedade, convencionada como a norma culta, seja ensinada de maneira sistemática, possibilitando aos alunos o bilinguismo: a língua que falam precisará coexistir com a língua que escrevem/escreverão.

Assim, com este trabalho, é preciso ficar claro que não se propõe que o professor ensine estruturas de PB dialetal aos alunos, pois isso os alunos já sabem. Porém, o conhecimento da descrição e análise das regras que subjazem ao PB dialetal é que são importantes. Portanto, não se propõe, em princípio, que esses estudos sejam usados diretamente na escola, mas indiretamente. Assim, o professor conhecerá a gramática do aluno e poderá elaborar formas de intervenção para ensino da gramática padrão, sem desvalorizar ou estigmatizar as formas não padrão dominadas pelo aluno e utilizadas em sua comunidade linguística.

Uma das formas de intervenção pode ser exteriorizar as diferenças entre português não padrão e português padrão. Por exemplo, no que se refere às regras de concordância nominal, conforme visto previamente, pode-se explicitar, de forma simplificada, que, enquanto, em PB não padrão, somente os itens iniciais do DP são marcados com o morfema de plural, no PB padrão, todos os itens que comportam flexão são marcados com o morfema de plural. À medida que essas diferenças são exteriorizadas, o aluno entende, de forma explícita, que as regras do português padrão são de uma gramática outra que ele precisa aprender e que são diferentes daquelas regras da gramática ele domina.

Isso posto, uma das contribuições dos estudos sintáticos de PB dialetal é possibilitar aos professores que conheçam as regras que subjazem à gramática de PB não padrão e possam assim elaborar formas de intervenção na aprendizagem de PB padrão, como estabelecer comparações entre as regras do PB padrão e de variedades não padrão. Essa possibilidade de comparação entre uma gramática e outra é prevista por Lemle e Figueiredo Silva (2013, p. 114), quando afirmam que: "é importante que os pontos de contraste entre as gramáticas coexistentes sejam apontados, descritos e discutidos".

Além disso, mais uma contribuição dos estudos de PB dialetal, com base na sintaxe gerativa, está no entendimento de que as estruturas não são aleatórias, mas partem de regras regidas por universais, contendo parâmetros idênticos ou semelhantes em outras 
- | Sintaxe gerativa e ensino de gramática: contribuições de estudos em PB dialetal

línguas do mundo. Por exemplo, no caso da concordância nominal, foi visto, em Pereira (2016a, 2016b, 2017, 2018a, 2018b), que, no PB não padrão, a posição de cardinais funciona como fronteira sintática de modo que sintagmas à sua esquerda são marcados com o morfema de plural e sintagmas à sua direita não são marcados. Essa regra é compartilhada por outras línguas do mundo, como o finlandês e o estoniano, conforme demonstrado, respectivamente, por Danon (2011) e Norris (2014). No finlandês, "um traço de número (plural) está disponível somente acima da posição do numeral"8 (DANON, 2011, p. 302, tradução de PEREIRA, 2018a, p. 23). No estoniano, "material à esquerda do numeral é plural, e material à direita é singular"9 (NORRIS, 2014, p. 143, tradução de PEREIRA, 2018a, p. 24).

Conhecer essas regras é fundamental quando se ensina concordância em sala de aula, pois as regras que regem a concordância nominal em uma variedade não padrão são diferentes daquelas que regem a concordância em português padrão. Na comparação entre as variedades, evidencia-se que ambas apresentam concordância, com a diferença de que uma marca todos os elementos do DP com o morfema "-s", e outra, somente os sintagmas iniciais (que precedem NumP).

Além da concordância nominal em PB não padrão, observa-se, em Vitral e Ramos (2006), que "cê", "sô" e "es", formas reduzidas, respectivamente, de "você", "senhor" e "eles", não são aleatórias. Quando se ensinam pronomes, na escola, é preciso saber que essas formas reduzidas fazem parte de um processo histórico natural de gramaticalização, como aquele que transformou "vossa mercê" em "você". Na comparação entre português padrão e não padrão, ficará claro que essas formas são recorrentes em PB não padrão, embora não façam parte da norma padrão e sejam por ela evitadas. No entanto, não é por que se evita na norma padrão que a forma não siga uma regra e não esteja de acordo com um processo gramatical. Conhecer tais regras, ao trabalhar com pronomes em sala de aula, é importante para não se perpetuarem estigmas ao ensinar as formas de prestígio.

Além da concordância nominal e da gramaticalização de "senhor", "você" e "eles", observa-se, em Duarte e Diniz (2013, p. 92), que o redobro de clíticos, em estruturas como "eu te amo você", é um processo regular e sistemático. São estruturas que eram produtivas em outros estágios da língua portuguesa e que ocorrem em outras línguas românicas, como no espanhol. Trata-se de uma forma evitada no português padrão contemporâneo, mas comum na fala dos alunos e, então, uma forma que requer conhecimento de sua descrição, para o ensino de pronomes na aula de português.

8 No original: "a (plural) number feature is only available above the position of the numeral".

9 No original: "material to the left of the numeral is plural, and material to the right is singular". 
É nesse sentido que conhecer as descrições da gramática do PB dialetal pode inclusive contribuir para intervenções na aprendizagem do português padrão, pois se comparam as formas e se explicitam as semelhanças e diferenças entre algo já conhecido (a gramática do aluno) e algo a se aprender (a gramática do português padrão). É nesse sentido ainda que o ensino da norma culta deve se dar como língua estrangeira (L2), seguindo o que é proposto por Lemle e Figueiredo Silva (2013).

Outra contribuição dos estudos sintáticos em PB dialetal, para o ensino de gramática, é a valorização do conhecimento gramatical que o aluno traz consigo para a escola, isto é, do conhecimento que ele domina. Assim, segundo os PCNs,

Ao organizar atividades de análise linguística para possibilitar aos alunos a aprendizagem dos conteúdos selecionados, alguns procedimentos metodológicos são fundamentais para o planejamento do ensino: isolamento, entre os diversos componentes da expressão oral ou escrita, do fato linguístico a ser estudado, tomando como ponto de partida as capacidades já dominadas pelos alunos. (BRASIL, 1998, p. 79, grifo nosso).

Dessa forma, ao considerar os estudos sintáticos de PB dialetal, parte-se do reconhecimento de que os alunos já dominam uma gramática de alta complexidade antes de chegarem à escola. Parte-se ainda do reconhecimento de que essa gramática pode ser sistematizada por meio de descrição e análise linguística de suas regras. Tais estudos, portanto, apresentam descrição de estruturas não contempladas nas gramáticas tradicionais, mas recorrentes na fala. Trata-se do estudo minucioso de estruturas "inexistentes" na gramática tradicional, mas que são compartilhadas na fala dos alunos e em suas comunidades e, por isso, devem ser reconhecidas.

Além disso, mais uma contribuição dos estudos sintáticos de PB dialetal, para o ensino de gramática, consiste na valorização de formas muitas vezes estigmatizadas que passam a ser então compreendidas como formas de uma gramática coesa e complexa com suas regras particulares. Assim, no que se refere ao estudo e sistematização de variedades não padrão, as pesquisas sobre PB dialetal contribuem para a descrição dos fatos linguísticos, dentro da abordagem gerativa, com método e rigor científicos que escapam de problemas descritivos da gramática tradicional. Ademais, a análise em diagramas arbóreos permite visualizar a hierarquia e as relações sintáticas entre constituintes. Esse método de análise e pesquisa permite ao docente refletir sobre os arranjos sintáticos que formam as estruturas em questão, parte do conhecimento implícito gramatical dos alunos. 
- Sintaxe gerativa e ensino de gramática: contribuições de estudos em PB dialetal

Desse modo, os estudos em PB dialetal vêm a contribuir em duas direções: a primeira é a explicitação do conhecimento linguístico internalizado de uma gramática; a segunda é a potencialização da capacidade de reflexão epilinguística ${ }^{10}$ e metalinguística na formação dos professores que, por sua vez, poderão orientar a aquisição desses conhecimentos entre seus alunos, como se espera nos PCNs:

[...] não se podem desprezar as possibilidades que a reflexão linguística apresenta para o desenvolvimento dos processos mentais do sujeito, por meio da capacidade de formular explicações para explicitar as regularidades dos dados que se observam a partir do conhecimento gramatical implícito. (BRASIL, 1998, p. 78, grifo nosso).

Por exemplo, com base nos estudos sobre concordância nominal, expostos na primeira parte deste trabalho, pode-se propor uma atividade como a que se segue:

1) Compare as construções em (1) e (2).

(1) as bolsa amarela

(2) as bolsas amarelas

2) Que semelhança se observa em (1) e (2) na sua interpretação?

R.: Ambas as construções se referem a mais de uma bolsa.

3) Que diferenças se observam em (1) e (2) na sua marcação de plural?

R.: (2) apresenta morfema "-s" em todas as palavras, enquanto (1) apresenta morfema "-s" apenas no artigo "a".

4) Qual das estruturas é preferida em um uso formal, como, por exemplo, uma entrevista de emprego ou apresentação de um trabalho escolar?

R.: A construção em (2).

\begin{abstract}
10 “Nas atividades epilinguísticas a reflexão está voltada para o uso, no próprio interior da atividade linguística em que se realiza. Um exemplo disso é quando, no meio de uma conversa um dos interlocutores pergunta ao outro 'O que você quis dizer com isso?' [...] Em se tratando do ensino de língua, à diferença das situações de interlocução naturais, faz-se necessário o planejamento de situações didáticas que possibilitem a reflexão sobre os recursos expressivos utilizados pelo produtor/autor do texto - quer esses recursos se refiram a aspectos gramaticais, quer a aspectos envolvidos na estruturação dos discursos - [...] Já as atividades metalinguísticas estão relacionadas a um tipo de análise voltada para a descrição, por meio da categorização e sistematização dos elementos linguísticos. Essas atividades, portanto, não estão propriamente vinculadas ao processo discursivo; trata-se da utilização (ou da construção) de uma metalinguagem que possibilite falar sobre a língua. Quando parte integrante de uma situação didática, a atividade metalinguística desenvolve-se no sentido de possibilitar ao aluno o levantamento de regularidades de aspectos da língua, a sistematização e a classificação de suas características específicas" (BRASIL, 1998, p. 30).
\end{abstract}


5) Observe agora as estruturas em (3).

(3) a. a bolsa amarelas

b. a bolsas amarela

c. a bolsas amarelas

6) São construções possíveis na língua que você fala? Por quê?

R.: Não, porque o artigo ("a"), que deveria estar marcado com "-s" de plural, não está; e as palavras ("bolsa" e "amarela"), que não deveriam estar marcadas com "-s" de plural, estão.

7) Compare (1) e (3). Você conseguiria explicar por que (1) é gramatical (bem formada), mas não (3)?

(1) as bolsa amarela

(3) a. *a bolsa amarelas

b. *a bolsas amarela

c. *a bolsas amarelas

8) Existiria alguma regra que permite (1), mas impede (3)? Se sim, descreva-a. Para responder a esta pergunta, considere se há alguma influência da posição do numeral cardinal na estrutura, como se observa em $\left(1^{\prime}\right)$ e $\left(3^{\prime}\right)$.

$\left(1^{\prime}\right) \quad$ as (duas) bolsa amarela

(3') $\quad$ a. *a (duas) bolsa amarelas

b. *a (duas) bolsas amarela

c. *a (duas) bolsas amarelas

R.: Os dados em ( $\left.1^{\prime}\right)$ e (3') revelam que elementos à esquerda do cardinal devem ser marcados com o morfema de plural, enquanto elementos à direita são não marcados.

9) Que regra rege a concordância em (2)?

(2) as bolsas amarelas

R.: Em (2), todos os elementos (do sintagma, do grupo nominal, da expressão) são marcados com '-s' de plural.

0) Em que aspecto a regra que rege a concordância em (1') seria diferente da regra que rege a concordância em (2)?

$\left(1^{\prime}\right) \quad$ as (duas) bolsa amarela

1(2) as bolsas amarelas

R.: Em $\left(1^{\prime}\right)$, apenas elementos que precedem o cardinal são marcados com o morfema de plural. Diferentemente, em (2), essa regra não se aplica. Todos os elementos são marcados com o morfema de plural. 
- | Sintaxe gerativa e ensino de gramática: contribuições de estudos em PB dialetal

Nessa atividade, a questão 1 explora habilidades de observação das estruturas linguísticas de duas variedades do PB; a questão 2 evidencia o conteúdo proposicional veiculado nas estruturas indicadas; a questão 3 direciona para a reflexão sobre a marcação de plural nos elementos que compõem o sintagma, em ambas as variedades; a questão 4 destaca a forma de prestígio, valorizada em situações formais de uso; as questões 5, 6 e 7 testam diferentes combinações (possíveis e impossíveis) no uso do morfema de plural, em PB não padrão, e acessam a intuição sobre estruturas outras que a gramática (internalizada) do falante rejeita; a questão 7 conduz à descrição de uma regularidade na estruturação linguística que licencia um padrão de distribuição do morfema de plural e, em consequência, impede uma distribuição fora desse padrão; a questão 8 direciona para a sistematização dessa regularidade, considerando-se a existência de uma fronteira sintática, a posição do cardinal, na distribuição do morfema de plural; a questão 9 volta a dar ênfase ao padrão de concordância redundante; e, por fim, a questão 10, em complementação à questão 1, conduz a uma explicitação e sistematização da comparação dos padrões que regem a concordância nas variedades padrão e não padrão. Em resumo, a atividade traz à consciência regras do funcionamento da concordância nominal, fenômeno inerente à competência linguística do falante e comum às variedades tratadas, que se diferenciam pelo fato acionarem parâmetros distintos de realização do fenômeno (marcação redundante versus marcação à esquerda do cardinal).

Assim, os estudos sintáticos em PB dialetal contribuem na explicitação do conhecimento internalizado da gramática que os alunos dominam. Com base nessa metodologia, pode-se pôr em prática a noção de "ensinar" gramática não como uma transmissão de conhecimento, mas como possibilidade de refletir sobre os arranjos linguísticos e tornar explícitos conhecimentos internalizados, conforme propõem Silva e Pilati (2016) e Foltran (2013).

Dessa forma, a metodologia gerativa, aplicada aos estudos de PB dialetal, evidencia como o conhecimento internalizado pode ser explicitado e "radiografado". Com efeito, a análise formal representada nos diagramas arbóreos permite a explicitação das relações sintagmáticas, das fronteiras sintáticas e das hierarquias. Trata-se, portanto, de um modelo de análise linguística do qual os professores terão conhecimento para se basearem em suas reflexões sobre os fatos linguísticos. Nota-se que os PCNs estão abertos a novas fontes e abordagens, conforme excerto abaixo:

O modo de ensinar, por sua vez, não reproduz a clássica metodologia de definição, classificação e exercitação, mas corresponde a uma prática que parte da reflexão produzida pelos alunos [...] pela mediação do professor, do conhecimento gramatical produzido. Isso implica, muitas vezes, chegar 
a resultados diferentes daqueles obtidos pela gramática tradicional, cuja descrição, em muitos aspectos, não corresponde aos usos atuais da linguagem, o que coloca a necessidade de busca de apoio em outros materiais e fontes. (BRASIL, 1998, p. 29, grifo nosso).

Nessa perspectiva, o aluno do curso de Letras e o professor na educação básica precisam conhecer muito mais do que aquilo que devem efetivamente ensinar, conforme observado por Foltran (2013, p. 173). Dito isso, uma contribuição dos estudos sintáticos em PB dialetal é acrescentar conhecimento relevante à formação intelectual dos professores de português.

Por último, uma outra contribuição dos estudos de PB dialetal para o ensino de gramática é aguçar a percepção de professores e alunos para formas linguísticas presentes em sua comunidade e ainda não descritas na literatura. Com isso, é possível ao professor pensar em desenvolver projeto conjunto com os alunos para descrição e análise das regras que subjazem a tais estruturas, de modo a reconhecer e valorizar a intuição linguística para os dados disponíveis. Assim, promove-se uma iniciação ao pensamento investigativo em busca de novas descobertas no campo dos estudos da linguagem.

Em suma, dentre as contribuições dos estudos sintáticos de português não padrão para o ensino de gramática, destacam-se as seguintes:

1) reconhecimento da competência gramatical que o aluno traz consigo para a escola;

2) valorização de formas muitas vezes estigmatizadas, pela observação de que tais formas têm espaço de relevância e interesse nas pesquisas científicas;

3) descrição de estruturas não contempladas nas gramáticas tradicionais, mas recorrentes na fala dos alunos;

4) possibilidade de elaboração de formas de intervenção para ensino da gramática padrão, sem desvalorizar ou estigmatizar variantes não padrão, por exemplo, estabelecer comparações entre as regras do PB padrão e de variedades não padrão;

5) obtenção de uma visão científica e analítica das gramáticas envolvidas;

6) entendimento de que as estruturas não são aleatórias, mas partem de regras regidas por universais, contendo parâmetros idênticos ou semelhantes em outras línguas do mundo; 
- | Sintaxe gerativa e ensino de gramática: contribuições de estudos em PB dialetal

7) potencialização da capacidade de reflexão epilinguística e metalinguística na formação dos professores que, por sua vez, poderão orientar a aquisição desses conhecimentos entre seus alunos;

8) explicitação do conhecimento internalizado da gramática que os alunos dominam;

9) apresentação de um modelo de análise linguística do qual os professores terão conhecimento para se basearem em suas reflexões sobre os fatos linguísticos;

10) acréscimo de conhecimento relevante à formação intelectual dos professores de português.

\section{Considerações finais}

Neste artigo, buscou-se mostrar como pesquisas sobre PB dialetal, em sintaxe gerativa, podem contribuir para o ensino de gramática, na formação de professores e na educação básica.

Assim, na primeira parte do trabalho, selecionou-se para estudo a concordância nominal, em PB não padrão e em estruturas recorrentes no dialeto mineiro. Mostrou-se que o conhecimento da gramática dessa variedade pode ser usado para comparação com a gramática do PB padrão. Dessa forma, estudos que descrevem as regras de concordância em PB não padrão servem como parâmetro para se evidenciar a gramática da variedade falada pelo aluno, que é regida por regras derivadas de universais linguísticos.

Na segunda parte, investigaram-se estudos em teoria gerativa que tratam do ensino de gramática. A partir desses estudos, compreende-se que, ao chegar à escola, o aluno já domina uma gramática e que a descrição dessa gramática conduz a procedimentos no ensino de reflexão, categorização, sistematização linguística e exteriorização desse conhecimento internalizado.

Naterceiraparte, mostraram-secaminhos decontribuição dos estudosdePBdialetal, em sintaxe gerativa, para o ensino de gramática, tais como: possibilidade de comparação científica entre dois sistemas, padrão e não padrão; aquisição do conhecimento da descrição e análise do PB dialetal; e familiarização com a metodologia de análise gerativa que explicita os arranjos sintáticos e a organização das estruturas linguísticas, o que, por sua vez, favorece o desenvolvimento de habilidades metalinguísticas e epilinguísticas.

Em suma, estudos em sintaxe gerativa têm a contribuir para a formação de professores e em consequência para o ensino de gramática na educação básica. 


\section{Agradecimentos}

Este trabalho contou com o apoio do PIBIC/CNPq, em projeto registrado na PRPPG/UFVJM.

\section{Referências}

BRASIL. Parâmetros Curriculares Nacionais (PCNs). Língua Portuguesa. Terceiro e quarto ciclos do ensino fundamental. Brasília: MEC/SEF, 1998.

CHOMSKY, N. Knowledge of Language. Its Nature, Origin and Use. New York: Praeger, 1986.

COELHO, I. L.; GÖRSKI, E.M.; MAY, G.H.; SOUZA, C.M. Para conhecer Sociolinguística. São Paulo: Contexto, 2015.

DANON, G. Agreement and DP-Internal Feature Distribution. Syntax, v. 14, n. 4, p. 297$317,2011$.

DUARTE, F.; DINIZ, C. Eu te falei para você: redobro de pronomes? In: RAMOS, J.;

COELHO, S. (org.). Português brasileiro dialetal: temas gramaticais. Campinas: Mercado de Letras, 2013. p. 91-101.

FARACO, C. A. Norma culta brasileira: desatando alguns nós. São Paulo: Parábola, 2008.

FERREIRA, E.; VICENTE, H. Linguística gerativa e "ensino" de concordância na educação básica: contribuições às aulas de gramática. Linguagem \& Ensino, Pelotas, v. 18, n. 2, p. 425-455, jul./dez. 2015.

FOLTRAN, M. J. Ensino de Sintaxe: atando as pontas. In: MARTINS, M. A. (org.).

Gramática e Ensino (Coleção Ciências da Linguagem Aplicadas ao Ensino; v. 1). Natal: EDUFRN, 2013. p. 167-185.

FOLTRAN, M. J.; KNÖPFLE, A.; CARREIRA, M. A gramática como descoberta. Diadorim, Rio de Janeiro, Revista 19, v. 2, p. 27-47, jul./dez. 2017.

GÖRSKI, E.; COELHO, I. Variação linguística e ensino de gramática. Working Papers em Linguística, Florianópolis, v. 10, n. 1, p. 73-91, jan./jun. 2009. 
- | Sintaxe gerativa e ensino de gramática: contribuições de estudos em PB dialetal

HAUSER, M.; CHOMSKY, N.; FITCH, T. The Faculty of Language: What Is It, Who Has It, and How Did It Evolve? Science 298, p. 1569-1579, 2002.

KATO, M. A gramática nuclear e a língua I do brasileiro. In: MARTINS, M. A. (org.). Gramática e Ensino. (Coleção Ciências da Linguagem Aplicadas ao Ensino; v. 1). Natal: EDUFRN, 2013. p. 149-166.

KAYNE, R. Movement and Silence. Oxford; New York: Oxford University Press, 2005.

KENNEDI, E. Possíveis contribuições da linguística gerativa à formação do professor de língua portuguesa. Revista de Letras, n. 32, v.1, p. 72-79, jan./jun. 2013.

LEMLE, M.; FIGUEIREDO SILVA, M. C. Variação na expressão da concordância: várias gramáticas e vários gramáticos. In: MARTINS, M. A. (org.). Gramática e Ensino. (Coleção Ciências da Linguagem Aplicadas ao Ensino; v. 1). Natal: EDUFRN, 2013. p. 99-118.

LOBATO, L. Linguística e ensino de línguas. In: PILATI, E.; NAVES, R.; VICENTE, H.; SALLES, H. (org.). Brasília: UnB, 2015.

MARTINS, M. A. (org.). Gramática e Ensino. (Coleção Ciências da Linguagem Aplicadas ao Ensino; v. 1). Natal: EDUFRN, 2013.

MIOTO C.; SILVA, M. C. F.; LOPES, R. E. V. Novo Manual de Sintaxe. Florianópolis: Insular, 2007.

NORRIS, M. A theory of nominal concord. Santa Cruz, California: 2014. Tese (Doutorado em Linguística) - University of California, Santa Cruz, 2014.

NUNES, J. Triangulismos e a sintaxe do português brasileiro. In: CASTILHO, A. de; KATO, M. (ed.). Descrição, história e aquisição do português brasileiro. Campinas: Pontes, 2007. p. 25-34.

PEREIRA, B. K. Inflection of "cada" and number feature valuation in BP. Estudos Linguísticos e Literários, v. 61, p. 85-103, 2018a.

PEREIRA, B. K. Exclamatives and interrogatives with "ques": the CP/DP hierarchy and the plural marking in Brazilian Portuguese. Signótica, v. 28, p. 581-612, 2016a. 
PEREIRA, B. K. Feature interpretability and the positions of $2^{\text {nd }}$ person possessives in Brazilian Portuguese. Filologia e Linguística Portuguesa (Online), v. 18, p. 199-229, 2016b.

PEREIRA, B. K. O possessivo de $2^{\text {a }}$ pessoa em PB dialetal. Caletroscópio, v. 6, p. 133-149, 2018b.

PEREIRA, B. K. The DP-internal distribution of the plural morpheme in Brazilian Portuguese. MIT Working Papers in Linguistics (Papers on Morphology, edited by Snejana lovtcheva and Benjamin Storme), v. 81, p. 85-104, 2017.

RAMOS, J.; COELHO, S. (org.). Português brasileiro dialetal: temas gramaticais. Campinas: Mercado de Letras, 2013.

PILATI, E. Teorias linguísticas e educação básica: proposta congregadora. In: BOECHAT, A.; NEVINS, A. (org.). O apelo das árvores. Campinas: Pontes, 2018.

PILATI, E.; NAVES, R.; VICENTE, H.; SALLES, H. Educação linguística e ensino de gramática na educação básica. Linguagem \& Ensino, Pelotas, v. 14, n. 2, p. 395-425, jul./dez. 2011.

QUAREZEMIN, S. Ensinar Linguística na escola: um confronto com a realidade. Working Papers em Linguística, Florianópolis, v. 18, n. 2, p. 69-92, ago./dez. 2017.

RAMOS, J.; COELHO, S. (org.). Português brasileiro dialetal: temas gramaticais.

Campinas: Mercados de Letras, 2013.

SCHER, A. P.; BARBOSA, J.; ARMELIN, P. R. Variação paramétrica e variação dialetal: uma análise para as construções dativas do inglês e do português brasileiro. Revista Veredas, v. 18, p. 138-160, 2014.

SILVA, T.; PILATI, E. Linguística gerativa e ensino de gramática na educação básica. In: PILATI, E. (org.). Temas em Teoria Gerativa: homenagem a Lúcia Lobato. Curitiba: Blanche, 2016. p. 231-240.

TESCARI NETO, A. Constituência sintática, ambiguidade estrutural e aula de português: o lugar da teoria gramatical no ensino e na formação do professor. Working Papers em Linguística, Florianópolis, v. 18, n. 2, p. 129-152, ago./dez. 2017. 
- | Sintaxe gerativa e ensino de gramática: contribuições de estudos em PB dialetal

VICENTE, H.; PILATI, E. Teoria Gerativa e 'Ensino' de Gramática: uma releitura dos Parâmetros Curriculares Nacionais. Verbum - Cadernos de Pós-Graduação, v. 2, p. 4-14, 2012.

VITRAL, L.; RAMOS, J. Gramaticalização: uma abordagem formal. Rio de Janeiro: Tempo Brasileiro; Belo Horizonte: FaLe/UFMG, 2006.

COMO CITAR ESTE ARTIGO: PEREIRA, Bruna Karla. Sintaxe gerativa e ensino de gramática: contribuições de estudos em PB dialetal. Revista do GEL, v. 17, n. 3, p. 234-259, 2020. Disponível em: https://revistadogel.gel.org.br/

DOI: http://dx.doi.org/10.21165/gel.v17i3.2867

Submetido em: 02/08/2020 | Aceito em: 01/10/2020. 